\title{
DISPONIBILIDADE DE SILÍCIO E BIOMASSA DE MILHO EM SOLO CONTAMINADO POR CHUMBO TRATADO COM SILICATO
}

\author{
Availability of silicon and maize biomass in a lead contaminated soil treated with silicate \\ Josângela do Carmo Trezena de Araújo ${ }^{1}$, Clístenes Williams Araújo do Nascimento², \\ Fernando Ferreira da Cunha Filho ${ }^{3}$
}

\begin{abstract}
RESUMO
A absorção de Si pelas plantas tem resultado em efeitos benéficos e amenizantes da fitotoxicidade de metais pesados, o que pode melhorar a fitoextração de metais do solo em razão do aumento da tolerância das plantas ao metal. Os níveis críticos de Si no solo, em relação a algumas espécies de plantas, ainda estão sendo estabelecidos no Brasil. No entanto, ainda não está definido qual o melhor extrator a ser usado. Neste trabalho objetivou-se avaliar a eficiência dos métodos de extração de Si (cloreto de cálcio, ácido acético, ácido cítrico e água), além de determinar a produção de matéria seca, teor e conteúdo de silício em plantas de milho em solo contaminado por chumbo. As doses de 0, 100, 250, 350 e $500 \mathrm{mg} \mathrm{kg}^{-1} \mathrm{de} \mathrm{Si}$, foram aplicadas em vasos de 5,5 dm $\mathrm{dm}^{-3}$, cultivados com plantas de milho por 65 dias. Com aplicação de doses de Si maiores que $100 \mathrm{mg} \mathrm{kg}^{-1}$ houve redução da produção de matéria seca de plantas de milho cultivadas no solo contaminado. A adição de doses crescentes de $\mathrm{Si}$ ao solo contaminado promoveu aumento dos teores de Si na parte aérea e raiz das plantas. O cloreto de cálcio e o ácido acético foram os extratores que mais se correlacionaram com os teores de Si extraídos pelas plantas.
\end{abstract}

Termos para indexação: Extratores de Si, contaminação do solo, fitorremediação.

\begin{abstract}
The absorption of silicon by plants can result in the amelioration of heavy metal phytotoxicity, thereby improving phytoextraction due to increased plant tolerance. The critical levels of $\mathrm{Si}$ in the soil for plant species in Brazil are still being discussed, however the best extractant for Si has not yet been defined. This work aimed to evaluate the effectiveness of methods for $\mathrm{Si}$ extraction from soil (calcium chloride, acetic acid, citric acid, and water). In addition, the biomass yield, concentration and content of $\mathrm{Si}$ in maize plants grown in a Pb-contaminated soil were also studied. Si was applied at the rates $0,100,250,350$, and $500 \mathrm{mg} \mathrm{kg}^{-1}$ in $5.5 \mathrm{dm}^{-3}$ pots in which 65 day old plants were cultivated. The Si doses promoted biomass reduction but increased the Si concentration in roots and shoots. The application of Si doses greater than $100 \mathrm{mg} \mathrm{kg}-1$ decreased the biomass yield of corn plants grown in contaminated soil. Calcium chloride and acetic acid were extractants that correlated significantly with the concentration of $\mathrm{Si}$ in plants.
\end{abstract}

Index terms: Si extractants, soil contamination, phytoremediation.

( Recebido em 19 de junho de 2009 e aprovado em 23 de março de 2011)

\section{INTRODUÇÃO}

Segundo Korndörfer et al. (2002), devido ao fenômeno de dessilicatização, os solos tropicais e subtropicais geralmente possuem baixos teores de silício disponível para as plantas. A disponibilidade do silício nos solos, bem como sua absorção e acumulação pelas plantas, não tem sido estudada com tanta intensidade quando comparado aos elementos essenciais.
Existem alguns extratores de silício eficientes citados na literatura, como água, ácido acético, cloreto de cálcio e ácido cítrico. Segundo Barbosa Filho et al. (2000), a idéia de utilizar água como extrator provém do fato de que o Si extraível em água representa a concentração na solução do solo em equilíbrio com o sistema solo (fator intensidade), enquanto o Si extraível em solução de fosfato acidificado representa a quantidade de $\mathrm{Si}$ que permanece no solo numa forma

${ }^{1}$ Universidade Federal Rural de Pernambuco/UFRPE - Departamento de Agronomia/DEPA - Rua Dom Manuel de Medeiros s/n - Dois Irmãos - 52171-900 Recife, PE - jctrezena@hotmail.com

${ }^{2}$ Universidade Federal Rural de Pernambuco/UFRPE - Departamento de Agronomia/DEPA - Recife, PE

3Universidade Federal de Pernambuco/UFPE - Recife, PE

Ciênc. agrotec., Lavras, v. 35, n. 5, p. 878-883, set./out., 2011 
adsorvida (fator quantidade). Assim, ambos os métodos de extração podem fornecer informações diferentes, mas úteis.

O extrator ácido acético é um ácido fraco que tem a capacidade de extrair o Si "disponível" para as plantas sem atacar de forma muito agressiva os minerais de argila, porém com capacidade para solubilizar pequenas cadeias de $\mathrm{Si}$ polimerizado (KORNDÖRFER et al., 1999). Para esses autores, sua utilização em solos que receberam a aplicação recente de calcário tende a superestimar os valores de silício "disponível" para as plantas. Segundo Korndörfer et al. (2004), o extrator cloreto de cálcio é um sal que tem a capacidade de extrair o Si "disponível" que se encontra principalmente na solução do solo, podendo extrair algumas formas pouco polimerizadas. Este extrator, ao contrário do que acontece com o ácido acético, não sofre a interferência do calcário recentemente aplicado.

Como a quantidade de $\mathrm{Si}$ varia com o extrator e com as propriedades do solo, essas extrações têm apresentado graus variados de sucesso para diagnose da disponibilidade desse elemento. Diante disso, faz-se necessário estudar métodos eficientes para a análise de $\mathrm{Si}$ disponível no solo, visando unificar um método eficiente, especialmente para os solos do Nordeste, onde esses estudos são escassos.

Na literatura, a ação do Si na imobilização de metais pesados no solo é reconhecida (LIANG et al., 2005, 2007). Porém, enquanto alguns autores afirmam que o Si ameniza a fitotoxicidade de metais por diminuir a biodisponibilidade destes elementos em decorrência da elevação do $\mathrm{pH}$ do solo (PAIM et al., 2006), outros defendem a imobilização como consequência do efeito direto do $\mathrm{Si}$ em solução, independentemente de alterações no $\mathrm{pH}$ do solo (LIANG et al., 2005; CUNHA et al., 2008).

O objetivo desse trabalho foi avaliar a eficiência dos métodos de extração de $\mathrm{Si}$ (cloreto de cálcio, ácido acético, ácido cítrico e água), além de determinar a produção de matéria seca, teor e conteúdo de silício em plantas de milho em solo contaminado por chumbo, visando à utilização de silicatos em ensaios de fitoextração.

\section{MATERIAL E MÉTODOS}

O solo utilizado neste experimento, classificado de acordo com o Sistema Brasileiro de Ciência do Solo como Espodossolo, foi obtido no município de Rio TintoParaíba, em uma área de deposição de escórias de uma empresa recicladora de baterias automotivas. O solo foi coletado na camada superficial de $0-20 \mathrm{~cm}$, seco ao ar, destorroado, peneirado com peneira de $2 \mathrm{~mm}$ de malha e caracterizado química e fisicamente (EMPRESA BRASILEIRA DE PESQUISA AGROPECUÁRIA -
EMBRAPA, 1997, 1999). As características do solo são: pH 3,63 (solo:água 1:2.5); $\mathrm{Al}^{3+} 0,80 \mathrm{cmol}_{\mathrm{c}} \mathrm{dm}^{-3} ; \mathrm{Ca}^{2+} 0,65$ $\mathrm{cmol}_{\mathrm{c}} \mathrm{dm}^{-3} ; \mathrm{Mg}^{2+} 0,57 \mathrm{cmol}_{\mathrm{c}} \mathrm{dm}^{-3} ; \mathrm{P} 3,24 \mathrm{mg} \mathrm{dm}^{-3} ; \mathrm{K}^{+} 0,03$ $\mathrm{cmol}_{\mathrm{c}}^{\mathrm{c}} \mathrm{dm}^{-3} ; \mathrm{Na}^{+} 0,27 \mathrm{cmol}_{\mathrm{c}} \mathrm{dm}^{-3} ; \mathrm{H}^{+}+\mathrm{Al}^{3+} 5,06 \mathrm{cmol}_{\mathrm{c}} \mathrm{dm}^{-3} ;$ carbono orgânico $9,21 \mathrm{~g} \mathrm{~kg}^{-1}$; areia $948 \mathrm{~g} \mathrm{~kg}^{-1}$; silte $22 \mathrm{~g} \mathrm{~kg}^{-1} \mathrm{e}$ argila $30 \mathrm{~g} \mathrm{~kg}^{-1}$. O teor total de $\mathrm{Pb}$ no solo obtido por águarégia (ABREU et al., 2001) foi $544 \mathrm{mg} \mathrm{dm}^{-3} \mathrm{e}$ o teor de $\mathrm{Pb}$ disponível por Mehlich-1 (FILIPPO; RIBEIRO, 1997) foi $23,16 \mathrm{mg} \mathrm{dm}^{-3}$.

Para utilização no experimento, o solo foi seco ao ar, destorroado, homogeneizado e passado em peneira de $4 \mathrm{~mm}$ de abertura de malha. A acidez do solo foi corrigida, utilizando carbonato de cálcio e magnésio P.A. (na proporção molar de 3:1), em quantidades previamente definidas em ensaio de incubação, visando elevar o $\mathrm{pH} \mathrm{em}$ $\mathrm{H}_{2} \mathrm{O}$ para a faixa de 6,0-6,2.

Após período de 23 dias incubados a $80 \%$ da capacidade de campo para a correção da acidez do solo, os vasos plásticos, com $5,5 \mathrm{dm}^{-3} \mathrm{de}$ solo, foram adubados com $200 \mathrm{mg} \mathrm{dm}^{-3}$ de $\mathrm{N}\left(\mathrm{KNO}_{3}\right),\left(\mathrm{NH}_{4}\right)_{2} \mathrm{SO}_{4},\left(\mathrm{NH}_{4} \mathrm{H}_{2} \mathrm{PO}_{4}\right)$ e $\left(\mathrm{NH}_{4}\right)_{2} \mathrm{HPO}_{4} ; 150 \mathrm{mg} \mathrm{dm}^{-3} \mathrm{deK}\left(\mathrm{K}_{2} \mathrm{SO}_{4} \mathrm{e} \mathrm{KNO}_{3}\right) ; 250 \mathrm{mg} \mathrm{dm}^{-3}$ de P $\left(\left[\mathrm{NH}_{4}\right]_{2} \mathrm{HPO}_{4} \mathrm{e} \mathrm{NH}_{4} \mathrm{H}_{2} \mathrm{PO}_{2}\right) ; 52 \mathrm{mg} \mathrm{dm}^{-3} \mathrm{de} \mathrm{S}\left(\mathrm{K}_{2} \mathrm{SO}_{4}\right)$, $\left(\mathrm{NH}_{4}\right)_{2} \mathrm{SO}_{4}, \mathrm{FeSO}_{4}, \mathrm{ZnSO}_{4}$ e CuSO$\left.{ }_{4}\right) ; 3,664 \mathrm{mg} \mathrm{dm}^{-3} \mathrm{de} \mathrm{Mn}$ $\left(\mathrm{MnCl}_{2} 4 \mathrm{H}_{2} \mathrm{O}\right) ; 4 \mathrm{mg} \mathrm{dm}^{-3} \mathrm{deZn}\left(\mathrm{ZnSO}_{4} 7 \mathrm{H}_{2} \mathrm{O}\right), 1,329 \mathrm{mg} \mathrm{dm}^{-3}$ $\mathrm{de} \mathrm{Cu}\left(\mathrm{CuSO}_{4}\right), 1,556 \mathrm{mg} \mathrm{dm}^{-3} \mathrm{de} \mathrm{Fe}\left(\mathrm{FeSO}_{4} 7 \mathrm{H}_{2} \mathrm{O}\right), 1 \mathrm{mg} \mathrm{dm}^{-3}$ de $\mathrm{B}\left(\mathrm{H}_{3} \mathrm{BO}_{3}\right)$ e $0,15 \mathrm{mg} \mathrm{dm}^{-3} \mathrm{de} \mathrm{Mo}\left(\mathrm{Na}_{2} \mathrm{MoO}_{4} 2 \mathrm{H}_{4} \mathrm{O}\right)$.

Após sete dias da adubação foram adicionadas as doses de silício na forma de silicato de cálcio de $0,100,250$, 350 e $500 \mathrm{mg} \mathrm{dm}^{-3}$ e posteriormente, seis sementes de milho da cultivar AG1051 foram semeadas nos vasos, sendo cultivadas apenas duas plantas após o desbaste. Os vasos foram irrigados com água destilada diariamente. Após 65 dias de cultivo, a parte aérea e as raízes das plantas foram coletadas. As raízes foram lavadas abundantemente em água de torneira e em água destilada. Em seguida, juntamente com a parte aérea, foram secas em estufa com circulação forçada de ar a $70^{\circ} \mathrm{C}$, até peso constante para obtenção da massa seca da parte aérea e de raízes. Posteriormente, foram trituradas em moinho tipo Wiley e analisadas. O silício acumulado nas raízes e parte aérea foi extraído de acordo com o método "amarelo" descrito por Korndörfer et al. (2004). Logo após a coleta das plantas, as amostras do solo foram secas, homogeneizadas e passadas em peneira de $2 \mathrm{~mm}$ de abertura de malha, sendo coletadas subamostras para determinação dos teores disponíveis de Si extraídos por água, ácido acético $0,5 \mathrm{~mol} \mathrm{dm}^{-3}$, cloreto de cálcio $0,01 \mathrm{~mol} \mathrm{dm}^{-3}$ e ácido cítrico $0,25 \mathrm{~mol} \mathrm{dm}^{3}$, na relação de 1:10, seguidas de agitação por 1 hora e repouso por 20 minutos para a decantação das argilas suspensas e posterior filtragem e determinação. Em alíquota de $10 \mathrm{~cm}^{3}$, 
acrescentou-se ao extrato $1 \mathrm{~mL}$ da solução sulfo-molíbdica a $75 \mathrm{~g} \mathrm{dm}^{-3}$, após 10 minutos adicionou-se mais $2 \mathrm{~mL}$ da solução de ácido tartárico a $200 \mathrm{~g} \mathrm{dm}^{-3}$ e, após 5 minutos , $10 \mathrm{~mL}$ da solução de ácido ascórbico a $3 \mathrm{~g} \mathrm{dm}^{-3}$. Após $1 \mathrm{~h}$ foram realizadas as leituras das amostras em espectrofotômetro a 660 nm (KORNDÖRFER et al., 2004).

$\mathrm{O}$ ensaio foi montado em delineamento em blocos casualizados, utilizando-se 5 doses de $\mathrm{Si}$, com três repetições e os dados obtidos foram submetidos à análise de variância, equações de regressão e correlação entre o Si absorvido pelas plantas e o determinado pelos extratores químicos, utilizando-se o software SAEG 9.0 (Sistema para Análises Estatísticas) da Universidade Federal de Viçosa.

\section{RESULTADOS E DISCUSSÃO}

Com o aumento das doses de $\mathrm{Si}$ adicionadas ao solo houve redução da produção de matéria seca de plantas de milho cultivadas no solo contaminado (Figura 1). Esse fato pode ser parcialmente atribuído à redução da disponibilidade de alguns nutrientes decorrentes do aumento do $\mathrm{pH}$ ou da precipitação de silicatos, o que pode ser observado quando o Si é adicionado em doses mais elevadas. Antes da adição de $\mathrm{Si}$, a disponibilidade de $\mathrm{Pb}$ por $\mathrm{CaCl}_{2}$ era de $2,28 \mathrm{mg} \mathrm{kg}^{-1} \mathrm{a}$ partir da adição da dose $100 \mathrm{mg} \mathrm{kg}^{-1}$ de $\mathrm{Si}$, o Pb disponível deixou de ser detectado no solo, comprovando a precipitação de $\mathrm{Pb}$ e outros nutrientes na forma de silicatos. $\mathrm{O}$ aumento do $\mathrm{pH}$ e a adição de $\mathrm{Ca}$ ao meio pode ter provocado a insolubilização de nutrientes, especificamente $P$, o que pode ter resultado na diminuição da produção de matéria seca. Além disso, micronutrientes como $\mathrm{Fe}, \mathrm{Cu}, \mathrm{Zn}$ e $\mathrm{Mn}$ podem ter precipitado com o aumento do $\mathrm{pH}$. Vale salientar, porém, a tendência inicial de aumento da produção de matéria seca tanto da raiz como da parte aérea com a adição das menores doses de Si (Figura 1). O aumento observado até a dose de $100 \mathrm{mg} \mathrm{kg}^{-1}$ pode ser facultado ao efeito benéfico do Si sobre a planta e a amenização da toxicidade de $\mathrm{Pb}$ pela precipitação do metal na forma de silicatos.

Resultados semelhantes foram relatados por Liang et al. (2005) e Cunha et al. (2008). Segundo esses autores, menores doses de Si são suficientes para amenizar a toxicidade de metais às plantas. Liang et al. (2005), investigando o efeito do Si no solo, conduziram dois experimentos paralelos que diferiram apenas na dose de $\mathrm{Si}$ aplicada ao solo, $400 \mathrm{mg} \mathrm{kg}^{-1}$ de $\mathrm{Si}$ no primeiro experimento e $50 \mathrm{mg} \mathrm{kg}^{-1}$ de $\mathrm{Si}$ no segundo experimento e concluíram que a dose de $50 \mathrm{mg} \mathrm{kg}^{-1}$ foi suficiente para amenizar os efeitos tóxicos de $\mathrm{Cd}$ em plantas de milho sem que houvesse alterações significativas no $\mathrm{pH}$ do solo.

De fato, alguns autores relatam que a aplicação de doses maiores que $100 \mathrm{mg} \mathrm{dm}^{-3}$ de $\mathrm{Si}$ ao solo promove a mudança da coordenação do Si de quatro para seis, sendo esse o ponto de partida para sua polimerização e conseqüente formação de complexos insolúveis Si-metal no solo (DIETZEL, 2000; PAIM et al., 2006). Paim et al. (2006) constataram a presença de corpúsculos esbranquiçados sobre as partículas de solo quando houve um aumento brusco da dose de 6.040 para $13.660 \mathrm{mg} \mathrm{dm}^{-3} \mathrm{de} \mathrm{Si}$.

$\mathrm{A}$ adição de doses crescentes de $\mathrm{Si}$ ao solo contaminado promoveu aumento linear e altamente significativo dos teores de Si na parte aérea das plantas (Figura 2). Para a raiz, foi também observado aumento do teor de Si (Figura 2). A partir da dose de $100 \mathrm{mg} \mathrm{kg}^{-1}$ de Si, verificam-se menores acréscimos no teor de Si acumulado, tanto na parte aérea como na raiz com o aumento das doses de Si no solo. Isso pode indicar diminuição da atividade dos ânions $\mathrm{SiO}_{3}^{-2}$ solúvel na solução do solo e aumento de sua participação como polímeros de $\mathrm{Si}$, atuando como ligantes para formação de complexos insolúveis deste elemento com metais no solo (PAIM et al., 2006).

$\mathrm{O}$ conteúdo de $\mathrm{Si}$, tanto na parte aérea, como na raiz, demonstrou aumento com a adição de doses crescentes de Si ao solo contaminado, com exceção das duas doses mais altas de Si para a raiz (Figura 3).

A adição de doses crescentes de Si foi acompanhada pelo aumento do teor de Si solúvel extraído por ácido acético e cloreto de cálcio (Quadro 1). O poder de recuperação dos extratores testados foi da seguinte ordem: água < ácido cítrico $<\mathrm{CaCl}_{2}<$ ácido acético. Pereira et al. (2003) verificaram que os ácidos cítrico e acético extraíram mais Si, enquanto que Korndörfer et al. (1999) verificaram que a água e o cloreto de cálcio foram os que menos extraíram $\mathrm{Si}$.

Com relação à eficiência dos métodos de extração de $\mathrm{Si}$, apenas foram eficientes na predição de Si disponível às plantas o cloreto de cálcio $(\mathrm{r}=0,97 * *)$ seguido do ácido acético $\left(\mathrm{r}=0,90^{*}\right)$. Os demais extratores não apresentaram correlações eficientes com os teores de Si extraídos pelas plantas (Quadro 2). A água e o ácido cítrico não foram eficientes em avaliar a disponibilidade de Si do solo (Quadro 1). As baixas quantidades de $\mathrm{Si}$ solubilizadas por estes extratores dificultaram sua determinação e correlação com a planta. Resultados semelhantes foram encontrados por Pereira et al. (2003, 2007), que relatam que a água foi pouco eficiente para extrair o Si das fontes testadas, resultando em extração média de menos de $0,05 \%$ do Si total.

De acordo com Korndörfer et al. (1999), a água como extrator de Si apresenta a inconveniência da dispersão que provoca nas partículas de argila, exigindo um tempo muito maior de decantação, antes da filtragem. Além disso, Carvalho et al. (2003) relatam a redução do teor de Si solúvel em água com o tempo de cultivo. Esses autores sugerem 
três possíveis explicações para a redução da capacidade extratora da água com o tempo: adsorção do $\mathrm{Si}$ às superfícies oxídicas da fração argila; insolubilização do elemento por precipitação e/ou absorção pelas plantas.
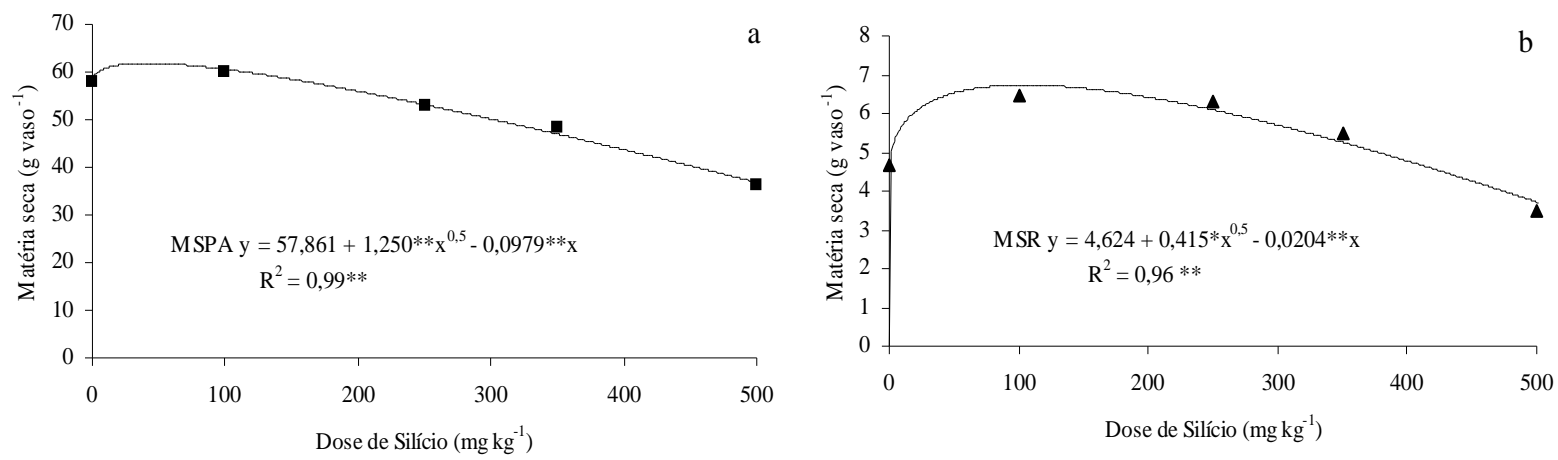

Figura 1 - Produção de matéria seca da parte aérea (a) e raiz (b) de milho após aplicação de doses crescentes de silício.

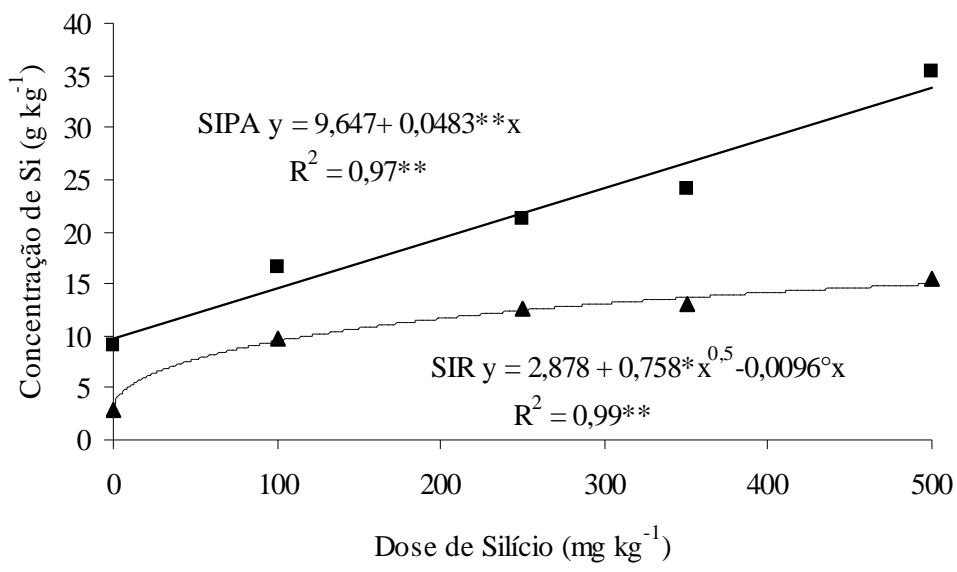

Figura 2 - Teor de Si na parte aérea e na raiz de milho após aplicação de doses crescentes de Si no solo contaminadn por $\mathrm{Pb}$.
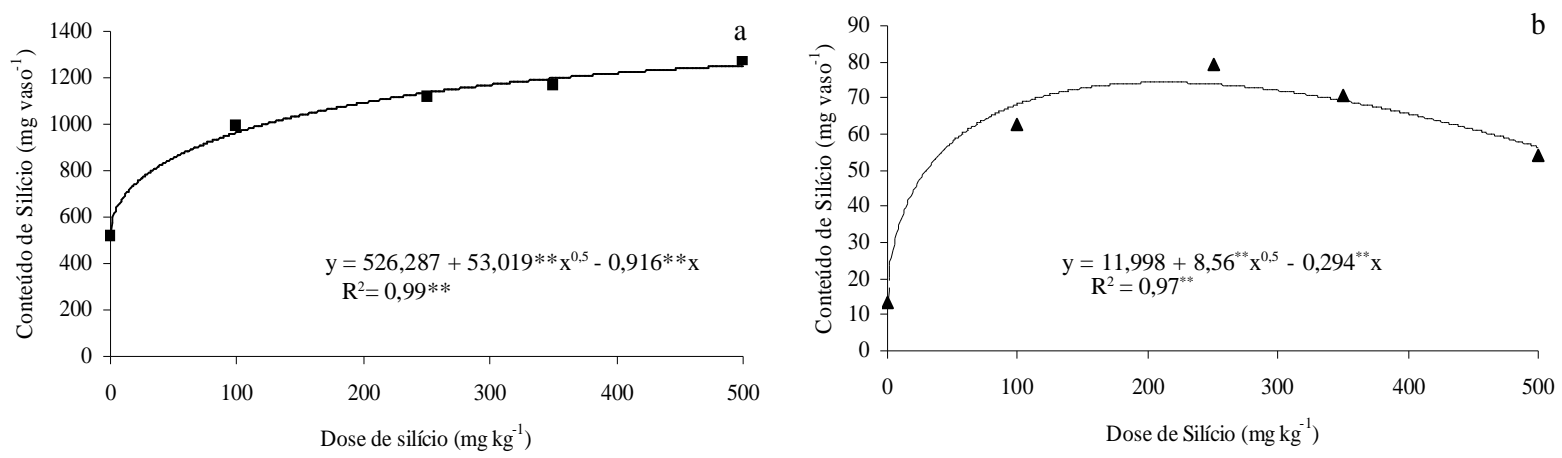

Figura 3 - Conteúdo de Si na parte aérea (a) e na raiz (b) de milho após aplicação de doses crescentes de Si ao solo contaminado por $\mathrm{Pb}$. 
Quadro 1 - Teores de Si disponível extraído por água, ácido cítrico, ácido acético e cloreto de cálcio em solo contaminado por $\mathrm{Pb}$ após aplicação de doses crescentes de Silício.

\begin{tabular}{|ccccc|}
\hline $\begin{array}{c}\text { DOSE } \\
\left(\mathrm{mg} \mathrm{kg}^{-1}\right)\end{array}$ & ÁGUA & Ácido Cítrico & $\begin{array}{c}\text { Ácido Acético } \\
\mathrm{dm}^{-3}-\end{array}$ & $\mathrm{CaCl}_{2}$ \\
\hline 0 & nd & 1,9 & 2,11 & 0,43 \\
100 & nd & 1,23 & 2,60 & 1,41 \\
250 & nd & 1,2 & 6,28 & 1,61 \\
350 & nd & 0,8 & 6,67 & 2,25 \\
500 & nd & 1,6 & 7,63 & 2,73 \\
Média & nd & 1,35 & 5,06 & 1,69 \\
C.V. $(\%)$ & - & 11,65 & 8,47 & 9,34 \\
\hline
\end{tabular}

nd (não detectado).

Quadro 2 - Coeficientes de correlação de Pearson entre a produção de matéria seca $\left(\mathrm{g} \mathrm{vaso}^{-1}\right)$, teor $\left(\mathrm{g} \mathrm{kg}^{-1}\right)$ e conteúdo $\left(\mathrm{mg}\right.$ vaso $\left.^{-1}\right)$ de silício na parte aérea e raiz das plantas de milho e teores disponíveis de Si obtidos com diferentes extratores químicos.

\begin{tabular}{|ccccccc|}
\hline & \multicolumn{2}{c}{ Matéria Seca } & \multicolumn{2}{c}{ Teor } & \multicolumn{2}{c|}{ Conteúdo } \\
& Parte aérea & Raíz & Parte aérea & Raíz & Parte aérea & Raíz \\
\hline Acido cítrico & $0,02^{\mathrm{ns}}$ & $-0,57^{\mathrm{ns}}$ & $-0,26^{\mathrm{ns}}$ & $-0,56^{\mathrm{ns}}$ & $-0,61^{\mathrm{ns}}$ & $-0,84^{*}$ \\
Acido acético & $-0,87^{*}$ & $-0,34^{\mathrm{ns}}$ & $0,90^{*}$ & $0,89^{*}$ & $0,86^{*}$ & $0,60^{\mathrm{ns}}$ \\
$\mathrm{CaCl}_{2}$ & $-0,85^{*}$ & $-0,33^{\mathrm{ns}}$ & $0,97^{* *}$ & $0,96^{* *}$ & $0,94^{* *}$ & $0,63^{\circ}$ \\
Teor PA & $-0,93^{* *}$ & $-0,48^{*}$ & - & $0,92^{* *}$ & $0,87^{*}$ & $0,50^{\mathrm{ns}}$ \\
Teor R & $-0,74^{\circ}$ & $-0,10^{\mathrm{ns}}$ & $0,92^{* *}$ & - & $0,99^{* *}$ & $0,80^{*}$ \\
\hline
\end{tabular}

$* * \mathrm{P}<0,01 ; * \mathrm{P}<0,05 ;{ }^{\text {ns }}-$ não significativo.

A maior recuperação de Si foi obtida com a solução de ácido acético. No entanto, a sua eficiência em predizer o teor disponível foi menor que o cloreto de cálcio. Resultado contrário foi obtido por Korndörfer et al. (1999), para os quais o ácido acético apresentou maior correlação com o teor absorvido pelas plantas que o cloreto de cálcio. No presente trabalho, a menor eficiência do ácido acético em relação ao cloreto de cálcio pode ser explicada pelo fato do ácido acético superestimar o teor de Si nos solos, principalmente nos corrigidos com calcário e naqueles que receberam a aplicação de fontes ricas em aluminossilicatos, como as escórias de alto-forno (PEREIRA et al., 2004).

\section{CONCLUSÕES}

Com a aplicação de doses de Si maiores que 100 mg $\mathrm{kg}^{-1}$ houve redução da produção de matéria seca de plantas de milho cultivadas no solo contaminado.

A adição de doses crescentes de Si no solo contaminado com $\mathrm{Pb}$ promoveu aumento dos teores de $\mathrm{Si}$ na parte aérea e raiz das plantas.
O cloreto de cálcio e o ácido acético foram os extratores que mais se correlacionaram com os teores de $\mathrm{Si}$ extraídos pelas plantas.

\section{REFERÊNCIASBIBLIOGRÁFICAS}

ABREU, C.A. et al. Comparação de métodos de análises para avaliar a disponibilidade de metais pesados em solos. Revista Brasileira de Ciência do Solo, Campinas, v.19, p.463-468, 1991.

BARBOSA FILHO, M. P. et al. Importância do silício para a cultura do arroz: uma revisão de literatura.

Informações Agronômicas, Piracicaba, v. 8, p. 1-9, mar. 2000.

CARVALHO, R.; CURI, N.; RESENDE, A.V. Absorção e translocação de silício em mudas de eucalipto cultivadas em Latossolo e Cambissolo. Ciência e Agrotecnologia, Lavras, v.27, n.3, p.491-500, maio/jun. 2003. 
CUNHA, K.P.V.; NASCIMENTO, C.W.A.; SILVA, A.J. Silicon alleviates the toxicity of cadmium and zinc for maize (Zea mays L.) grown on a contaminated soil.

Journal of Plant Nutrition and Soil Science, Tharandt, v.171, p.849-853, 2008.

DIETZEL, M. Dissolution of silicates and the stability of polysilicic acid. Geochimica et Cosmochimica Acta, London, v.64, p.3275-3281, 2000.

EMPRESA BRASILEIRA DE PESQUISA AGROPECUÁRIA. Manual de análises químicas de solos, plantas e fertilizantes. Brasília, 1999. 370p.

EMPRESA BRASILEIRA DE PESQUISA AGROPECUÁRIA. Manual de métodos de análise de solo. 2.ed. Rio de Janeiro, 1997. 212p.

FILIPPO, B.V. de; RIBEIRO, A.C. Análise química do solo. 2.ed. Viçosa, MG: UFV, 1997. 26p.

KORNDÖRFER, G.H. et al. Efeito do silicato de cálcio no teor de silício no solo e na produção de grãos de arroz de sequeiro. Revista Brasileira de Ciência do Solo, Campinas, v.23, p.635-641, 1999.

KORNDÖRFER, GH.; PEREIRA, H.S.; CAMARGO, M.S. Silicatos de cálcio e magnésio. 2.ed. Uberlândia: UFU, 2002.23p. (Boletim técnico, 1).
KORNDÖRFER, GH.; PEREIRA, H.S.; CAMARGO, M.S. Silicato de cálcio e magnésio na agricultura. Uberlândia: UFU/ICIAG, 2004. (Boletim técnico, 1).

LIANG, Y. et al. Mechanisms of silicon-mediated alleviation of abiotic stresses in higher plants: a review. Environmental Pollution, Barking, v.47, p.422428, 2007.

LIANG, Y.; WONG, J.W.C.; WEI, L. Silicon-mediated enhancement of cadmium tolerance in maize (Zea mays L.) grown in cadmium contaminated soil. Chemosphere, Oxford, v.58, p.475-483, 2005.

PAIM, L.A. et al. Estudo dos efeitos do silício e do fósforo na redução da disponibilidade de metais pesados em área de mineração. Química Nova, São Paulo, v.29, p.28-33, 2006.

PEREIRA, H.S. et al. Avaliação de fontes e de extratores de silício no solo. Pesquisa Agropecuária Brasileira, Brasília, v.42, n.2, p.239-247, fev. 2007.

PEREIRA, H.S.et al. Extratores de silício disponível em escórias e fertilizantes. Revista Brasileira de Ciência do Solo, Campinas, v.27, p.265-274, 2003.

PEREIRA, H.S. et al. Silicon sources for rice crop. Scientia Agricola, Piracicaba, v.61, p.522-528, 2004. 